\title{
The Course of Physics at the Technical University Digital Education System
}

\author{
Svetlana L. Timchenko ${ }^{1 *}$, Andrei V. Semikolenov ${ }^{1}$, Nikolai A. Zadorozhnyi ${ }^{1}$, Anatoly $S$. \\ Chuev $^{1}$, and Olga $Y u$. Dementeva ${ }^{1}$ \\ ${ }^{1}$ Bauman Moscow State Technical University, 2nd Baumanskaya str., 5/1, 105005, Moscow, Russia
}

\begin{abstract}
The paper considers the digital education possibilities for a technical university, using the online courses on general physics course sections example. Online courses in physics contain video lectures, seminars, video demonstrations, and test tasks. All course content is available on the "Open BMSTU" distance learning platform. Current students' knowledge assessment is carried out by testing in remote access mode. Test tasks have three levels of difficulty. Tests of the first complexity level allow you to evaluate the knowledge of physical quantities, laws, formulas definitions and assume the choice of the answer. Tests of the second complexity level contain problems that require knowledge of formulas and basic methods for solving problems. Tests of the third complexity level contain problems, the solution of which requires knowledge of formulas, logical thinking and provides for detailed problem-solving. Performing test task complexity determines the optimal ratio choice between the time taken to complete the test and the task content complexity level in the test. Regular testing allows not only to control but also to merge the information got at lectures, seminars and laboratory sessions.

We carried out the statistical processing of experimental groups test results on the general physics course "Electromagnetism" topics using the digital educational environment MOODLE and EDX.
\end{abstract}

\section{Introduction}

The transformation of the education system in Russian universities and the assessment of students' knowledge system, are associated with the transition to a competency-based approach [1]. At the same time, testing, as evaluating the students' knowledge method (bachelors and magicians), should reflect the competencies content. The Federal State Educational Standards (FSES) and Federal State Requirements (FSR) provides Russian Federation educational space unity, the continuity of basic educational programs, the educational programs appropriate education level content variability. It is possible to create educational programs of various complexity levels and orientation, taking into accounts the students' educational needs and abilities. FSES and FSR guarantee the required education level and quality based on the unity of obligatory requirements to

\footnotetext{
* Corresponding author: timch@bmstu.ru
} 
basic educational programs realization conditions and their development results. Educational standards are the basis for an aim assessment of compliance with the established requirements of educational activities and students training who have mastered educational programs of the appropriate level and direction, regardless of the education and training form [1-3].

Improving the education quality and, in general, educational services for students who receive first and second education, and for students who attend advanced training courses, requires the creation of the new methods for high-quality and mobile training of graduates. This applies to both universities, higher education institutions of natural science, and technical universities. The development of digital information technologies makes it possible, along with traditional methods of teaching, to create new educational methods to maintain the competitiveness of Russian universities at the world level in the education.

Creating an effective information educational environment of an educational institution is one of the main tasks of a modern university. It is necessary to create its own, competitive information and educational environment of the technical university as a higher educational institution that produces modern engineers in the innovative society and digital economy conditions. The changing institutional environment requires graduates to work through information and communication technologies, which in practice should provide the information and educational environment of the university [4, 5]. In general, the creation of online courses in physics, containing video lectures, seminars, demonstrations, and the development of a base for self-testing, allows you to supplement the formation of a digital educational platform of the technical university and adapt it for the educational process.

Improving the education quality requires a transition to continuous, dynamic teaching methods and technologies improvement. So we developed a new technology, including the introduction of information and computer technology in the learning process for learning disciplines in "Informatics and Computer science" field - read series of lecturesvisualizations that allowed effectively to improve the development of disciplines in this field of training of engineers [3].

New information technologies have proved their irreplaceable in the education systems of Western Europe and the United States [6-8]. They proved to be one guarantees of the educational process modernization, becoming a powerful way of self-education, increasing the education information content and intensity. However, the question of implementing information technologies benefits in the educational system of any educational institution, being far from new, remains open. At the moment, there are two points of view about the usefulness of education digitalization. The first point of view is optimistic, and the second is pessimistic. A proponent of the optimistic point of view on the need for education digitalization is an American scientist and teacher Norman Allison Crowder, who developed an extensive algorithm for programmed learning [8]. Pointing out historical milestones in creating a digital education base, we should note that the method of programmed learning was proposed by Professor B.F. Skinner in 1954 [9]. According to B.F. Skinner programmed learning is a training method based on a specially developed a training program, which is a specific sequence of specific tasks, by observing which the activities of the teacher and students are performed and controlled. According to N. Crowder's ideas about programmed learning: not only the general procedure for mastering the training material is necessary but also personal training programs of the programmed learning branched algorithm [8]. In a series of educational books "TutorText", they proposed a dialogic method of communication with the student, taking into account his capabilities. In 1960, Crowder prepared a computer training program "AutoTutor", which implements the ideas formulated in "Tutor Text". 
The pessimistic point of view on the information technologies introduction in the educational process is supported by the American teacher E. Delbanco [10]. The fears of pessimists are justified because they believe that the reckless promotion of uncontrolled self-study of students, armed with constantly improving gadgets, will harm the quality and efficiency of higher education. In particular, E. Delbanco believes that because of the unlimited availability of electronic tools and resources, there will be a disappearance of systemic academic higher education. The scientist believes that the prospects for a "bright future of education on the Internet" are impossible. According to Delbanco's opinions, rampant computerization promises a return to the worst pedagogical legacy of medieval universities, whose students often studied in any way and from anyone, but not from professional teachers [10].

On the other hand, as practice shows, modern information technology use breaks the established stereotypes of the educational process. In the age of informatization, mobile communications development, storage, and transformation of the received information, the teacher can no longer carry out the educational process conservatively. To explain the training material, he will have to use gadgets-mobile devices.

The student's digital portfolio (content) formation is carried out by the university with the university's educational structure support. In this regard, the creation of online courses at universities will improve the development of professional competencies by students - bachelor and masters, postgraduate students, students in programs of professional development and retraining for getting a second higher education $[4,5,11$ $15]$.

\section{Structure of Online Courses in Physics at a Technical University}

To use the digital education opportunities, BMSTU launched a project for the development of online courses "Open BMSTU" on basic disciplines that are offered for study by the faculty of Fundamental Sciences in 2018.

As a part of this project, the "Physics" department developed online courses on the basic physics course, which is part of the basic part of the "Open BMSTU" digital educational platform. The training results on the development of basic courses are correlated with the competencies described in the FSES.

The digital educational platform being formed at BMSTU, assumes a fundamental presentation and study of the basic course of physics at a technical university, with a possible emphasis on applied technical problems, current theories, ideas, concepts, laws, and concepts in modern physics. Each online physics course contains video lectures, video seminars, video demonstrations, and test tasks. Students from all the university's courses represented the audience.

\section{Experimental Testing of Students in the General Physics Course}

In the experiment on online courses introduction in the physics learning process of university students, we analyzed the course development with the use of remote testing groups of students at the "Engineering technology", "Informatics and control systems", and "Aerospace Technology" faculties.

The main task of testing during the program on creation of open digital education at the technical university "Open BMSTU" is the possibility of using a digital educational form for additional independent study of the physics course at the technical university, the 
possibility of dynamic control of students' knowledge in remote access mode, which requires regular work on the course content. A structured course on the university's digital platform allows you to provide a significantly larger volume of educational material and to activate the study of the course content by students.

We developed and approved the online course structure for the general physics course for the technical university. Next, in more detail, consider the online course "Electromagnetism". The course "Electromagnetism" contains lectures, seminars, and laboratory sessions. The number of lectures -9 , seminars -6 , laboratory works -4 . During laboratory work, students should perform and defend the experimental task, and two classes are allocated for boundary control, which allows you to control the current knowledge of students [1, 2].

We carried out current students' knowledge monitoring by weekly testing of students in computer classes. For this purpose, we developed test tasks, which contain tasks of three complexity levels on the topics of lectures and seminars. Tests of the first complexity level contain test tasks that require the student to know the definitions of physical quantities, laws, and formulas. This type of test presupposes the choice of an answer from the suggested answers. Tests of the second complexity level contain problems that require knowledge of formulas, and, as a rule, the problem can be solved using only one formula. The answer to the tasks of the second complexity level tests must be presented in the form of a formula or number. Tests of the third complexity level contain more complex tasks that require not only knowledge of formulas but also skills of their transformations. Solving each part of the test takes about 20 to 40 minutes on average, depending on the number of tasks and their solution complexity.

There is a test example from the section "Electromagnetism" on the topic "Power Wires in a Magnetic Field" below.

\subsection{Test example}

\section{Tasks of the 1st complexity level (formulas, definitions)}

1. The Biot-Savart law for the electric current.

2. Magnetic field strength measurement units.

3. Magnetic field induction measurement units.

4. Theorem on the circulation of the magnetic field intensity vector in the vacuum in integral and differential forms.

5. Magnetic moment of the power circuit.

6. The force acting on a frame with a current in a uniform magnetic field.

7. The force acting on a frame with a current in a nonuniform magnetic field, if the angle between the magnetic moment vector of the frame with a current and the induction vector of the external magnetic field is zero.

8. The rotational moment of forces acting on a power circuit in a uniform magnetic field.

9. The relationship between the magnetic induction $\boldsymbol{B}$ and the magnetic field strength $\boldsymbol{H}$ in a vacuum.

10. Magnetic field induction in the center of a circular current in a vacuum.

11. Magnetic field induction of a straight long conductor with a current.

12. Induction of the solenoid's magnetic field with current.

13. Potential energy of a power circuit in a uniform external magnetic field with induction $\boldsymbol{B}$.

14. Volumetric energy density of the magnetic field in a vacuum.

15. Gauss' theorem for vector $\boldsymbol{B}$ in integral and differential forms. 


\section{Tasks of the 2nd complexity level}

1. Considering the known the electron's orbit radius $R=0.53 \cdot 10^{-10} \mathrm{~m}$ (the first Bohr radius), the electron charge $e=1.6 \cdot 10^{-19} \mathrm{C}$, the electron mass $m=9.1 \cdot 10^{-31} \mathrm{~kg}$, the electric constant $\varepsilon_{0}=8.9 \cdot 10^{-12} \mathrm{~F} / \mathrm{m}$. The task is to determine the electron magnetic moment, which moves in a circular orbit around the proton (the Bohr model of the hydrogen atom).

2. On the disk surface of radius $R$ from the disk center to the edge $N$ turns of a thin wire spiral are tightly laid. The wire rings radius varies from zero from the center to $R$ at the spiral outer edge. The task is to determine the magnetic moment of a spiral if spiral amperage is $I$.

3. The power circuit of radius $R$ is located in a uniform external magnetic field with induction $\boldsymbol{B}$. The ampere forces moment $\boldsymbol{M}$ affected the circuit. The angle between the magnetic induction vector $\boldsymbol{B}$ and the frame magnetic moment vector is $60^{\circ}$. The task is to determine the amperage of the current circuit.

4. The coils have the same amperage $I$, the distance between them - $d$, the coils radius $-r,(r<<d)$, the number of turns in each of them $-N$. The task is to find the interaction force between two coils on the same axis.

5. What work is needed to turn a power circuit whose magnetic moment is $\boldsymbol{p}_{\boldsymbol{m}}$ in a uniform magnetic field with an induction $\boldsymbol{B}$ from the stable equilibrium position to the angle $\alpha$ ?

\section{Tasks of the 3rd complexity level}

1. The power circuit is in a stable equilibrium position in a uniform external magnetic field with an induction $B=3 \mu \mathrm{T}$, the circuit magnetic moment $-p_{m}=100 \mathrm{~A} \cdot \mathrm{cm}^{2}$. What work is needed to get the frame back to an angle equal, respectively $30^{\circ}, 60^{\circ}, 90^{\circ}, 180^{\circ}$ ?

2. The power circuit is in a stable equilibrium position in a uniform external magnetic field with an induction $B=11 \mu \mathrm{T}$, the circuit magnetic moment $-p_{\mathrm{m}}=10 \mathrm{~A} \cdot \mathrm{cm}^{2}$. What work will the Ampere forces do when the frame is rotated at an angle equal to, respectively $30^{\circ}, 60^{\circ}, 90^{\circ}, 180^{\circ}$ ?

3. A circular circuit of radius $R=10 \mathrm{~cm}$, with amperage $I=2 A$ is located in a uniform magnetic field with an induction of $B=5 \mu T$. What work will the forces of the magnetic field do when the contour is rotated from the unstable to the stable equilibrium position?

4. A circular circuit of radius $R=10 \mathrm{~cm}$, with amperage $I=2 \mathrm{~A}$ is located in a uniform magnetic field with an induction of $B=10 \mu T$. What work will the forces do when the contour is rotated from the stable to the unstable equilibrium position?

5. When turning a circuit in a uniform external magnetic field with induction $\boldsymbol{B}$, its potential energy increased by $\Delta W$, and the angle between the magnetic moment vector of the circuit and the vector $\boldsymbol{B}$ changed from 0 to $90^{\circ}$. Knowing the radius of the loop $R$, determine the circuit amperage.

Studying a physics course at a technical university using an online course containing weekly three-level testing allows you to productively use the hours of an independent work of students. Online courses help not only to work out the theory, that is, the lecture material but also to use the knowledge gained in solving practical problems and performing tasks of the laboratory workshop [16, 17]. Testing in remote access mode, conducted within the educational process through information technologies, allows for an active dialogue between the teacher and students. Using such technologies is necessary not only to simplify the educational process but also to form the educational competencies of future graduates $[1,2,15]$. 


\section{Experiment Results}

To test the online course's impact on the learning process quality, we tested students in the course sections "Electromagnetism". We chose groups from the IU faculty (Information and Control Systems) for testing [3]. There are testing IU faculty students' results on the course "Electromagnetism" in Fig. 1-5. Horizontally, scores are set aside for each correct answer. The program provided a score of one point for each correct answer. We show the number of participants who received correct answers vertically. There are diagrams in Fig. 1, 2, 5, that show the test results at the most optimal ratio between the complexity level of the test questions asked, and the time allotted to perform the test on three topics from the section "Electromagnetism". All students were at the same conditions for working on tests. The complexity level of the test tasks was also the same for all participants.

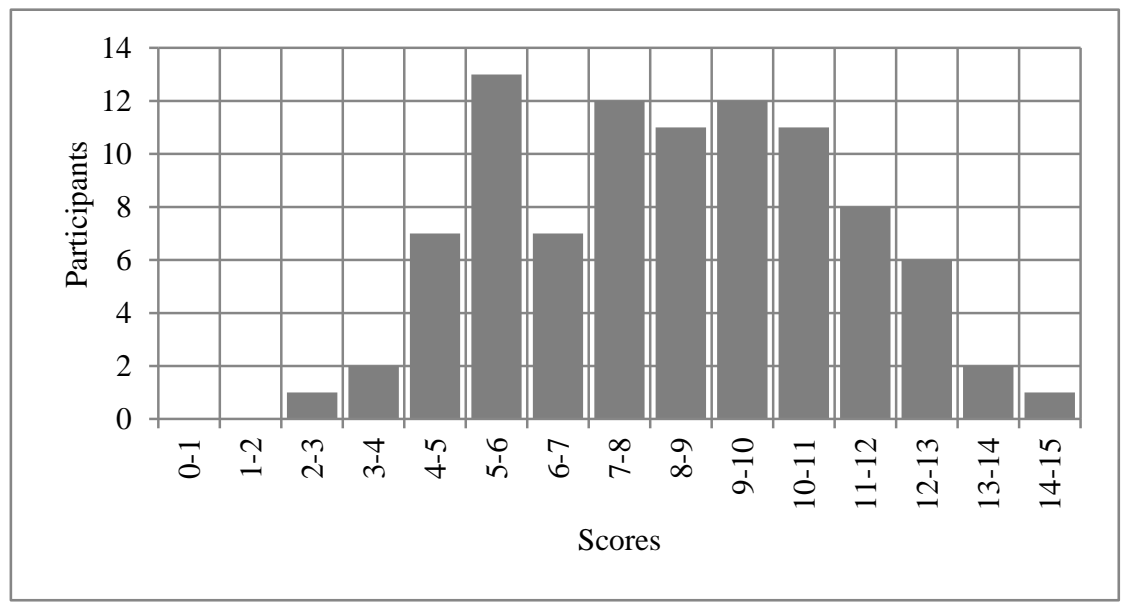

Fig. 1. Testing results on the topic "Magnetic Field in a Vacuum" with the optimal ratio of the questions complexity and the time for solving tasks.

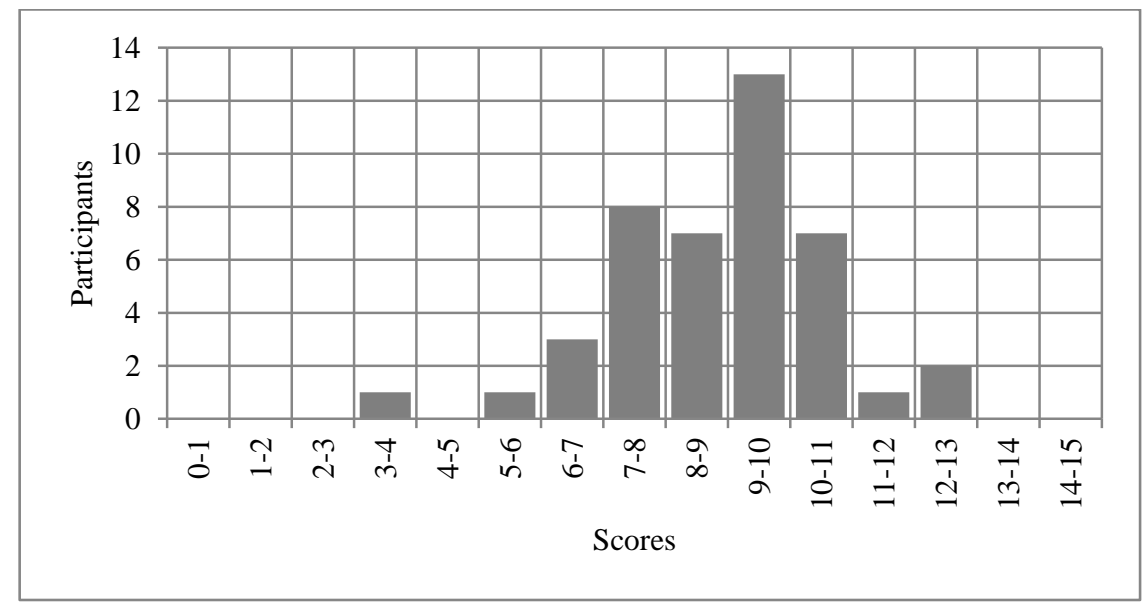

Fig. 2. Testing results on the topic "Charged Particles Movement in Electric and Magnetic Fields" with the optimal ratio of the questions complexity and the time for solving tasks. 


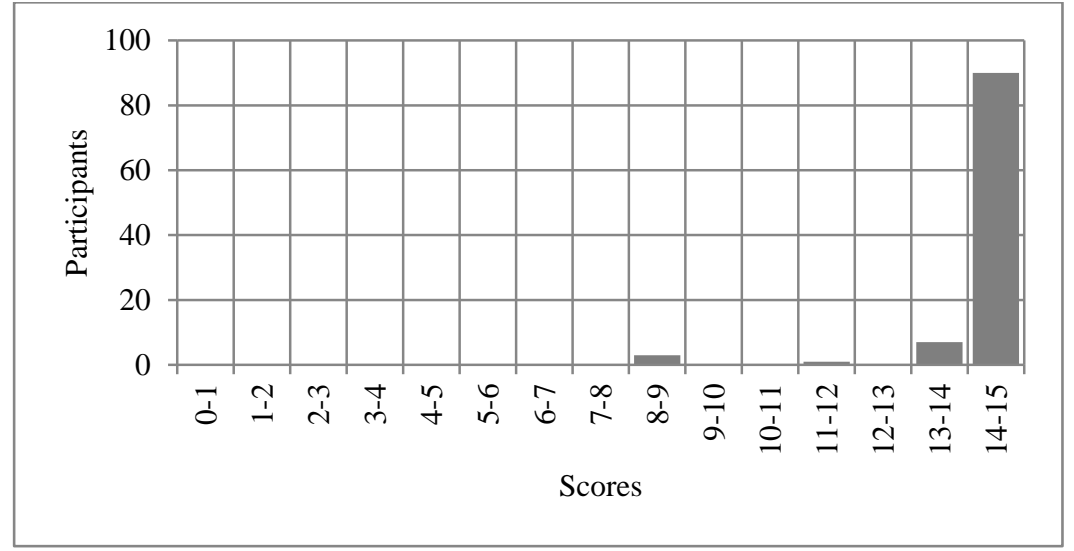

Fig. 3. Testing results on the topic "Magnetic Field in a Vacuum" for performing all test tasks with an extended time for solving tasks.

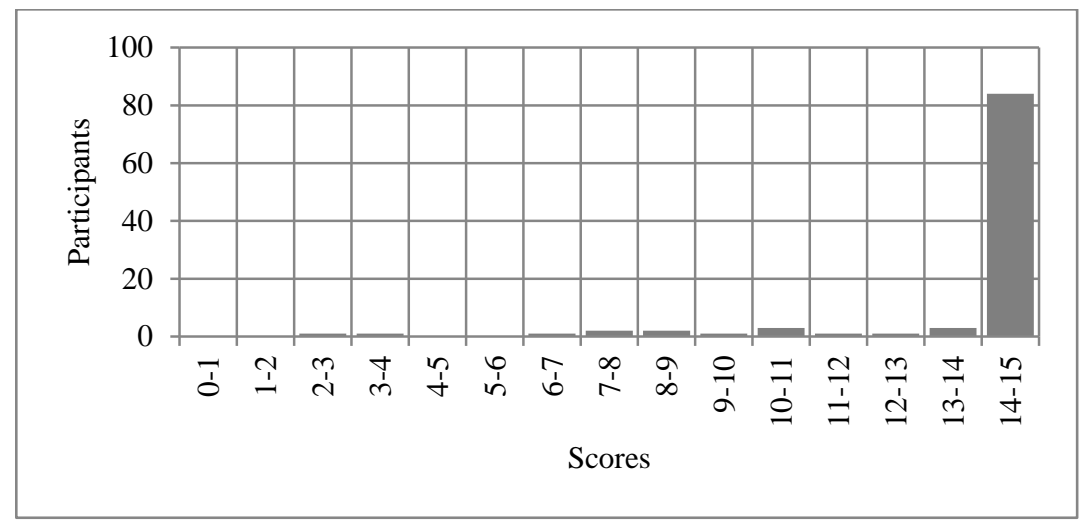

Fig. 4. Testing results on the topic "Charged Particles Movement in Electric and Magnetic Fields" with an extended time interval for solving tasks.

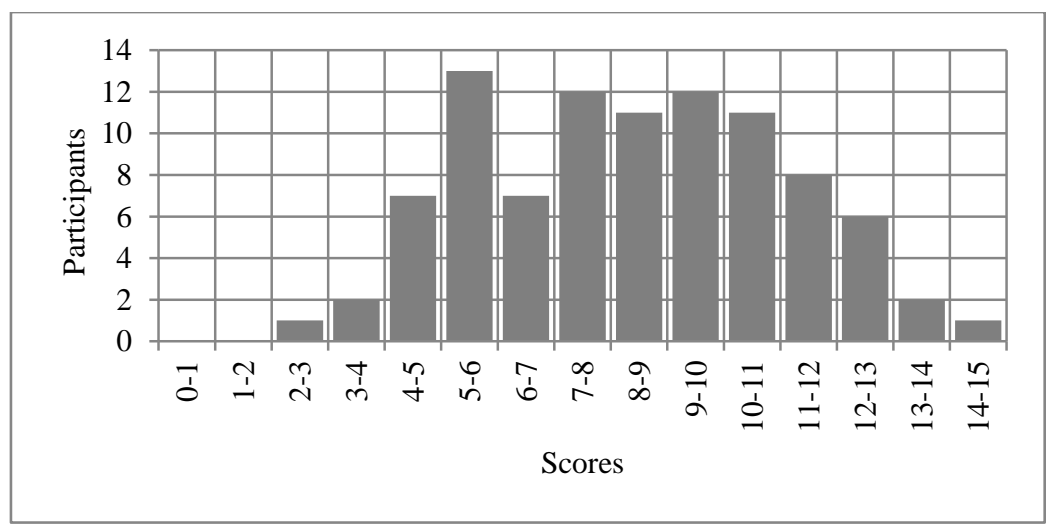

Fig. 5. Testing results on the topic "Conductors in a Magnetic Field" with the optimal ratio of the questions complexity and time for solving tasks. 


\section{Experiment Results}

We got diagrams, presented in this paper on fig. 1-5, using the digital educational environment on the MOODLE and EDX platforms. The diagrams show the distribution of points scored for solving tasks.

When creating test tasks and conducting testing:

- we adjusted the time allotted for solving the test tasks;

- we introduced the task complexity coefficient, which was used to determine the time interval allocated for solving test tasks.

You can see the testing results with the optimal ratio of the choice of the time interval allotted for the task and its complexity according to the topics from the section "Electromagnetism": "Magnetic Field in a Vacuum" (Fig. 1), "Charged Particles Movement in Electric and Magnetic fields" (Fig. 2), "Conductors in a Magnetic Field" (Fig. 5).

The points distribution received by students for solving test tasks in the section "Electromagnetism" (Fig. 1, 2, 5), shows that when choosing the optimal ratio between the tasks complexity and the allocated time interval for solving test tasks, on average (70$80) \%$ of students in the study group receive a score that shows satisfactory knowledge, and only (20-30)\% get good current knowledge and the score they receive later can be equivalent to the score of " 4 " and " 5 ".

Fig. 3, 4 show the test results for the same parts of the course "Electromagnetism", but with an increased time interval for solving test tasks and simplifying test tasks. We can see that in this case, almost all participants gain the maximum number of points.

At the same time, we should note that during testing, we didn't exclude the possibility of "cheating" with the use of, for example, gadgets, since one teacher usually carried out the testing in the classrooms, there is no means of additional control, for example, video control. Therefore, such testing is not fully informative, and it is hardly appropriate to use it for the educational process or students' self-education.

There is a relationship between the task complexity degree and the results of its completion. Approximately (20-30)\% of the group can cope with tasks of increased complexity. We should note that not always a student who can solve a complex test problem has a high exam score in this subject. To a greater extent, test results depend on students' current knowledge and practical skills in the subject.

To improve testing as a motivating factor and a way to control knowledge on a particular subject by selecting the most effective test questions, it is extremely interesting and important for teachers to get such distributions of correct answers (Fig. 1-5) and on specific questions asked in a further personal conversation. To get this information in the form of the visual diagrams, test questions should be numbered and grouped by subject, briefly showing the physical orientation of the block of questions. This requires additional technical efforts from the teacher and the corresponding capabilities of the program used $[13,15,18,19]$. Digital educational environments on the MOODLE and EDX platforms that were used in this experiment have accessible, adaptable software. At this stage, the MOODLE program is well adapted for a wide audience because of the greater volume of used platform features. For example, the MOODLE system contains tools for current statistical analysis of test results, which allows students to get a real-time final assessment of the work as a whole and for individual tasks. The teacher can set the rating scale and adjust the test tasks after the students pass the test. The capabilities of the EDX educational platform are not yet fully used. Improving the MOODLE and EDX programs will allow you to quickly analyze test results and optimize the testing process.

Information technologies made it possible to include active forms of learning in the educational process, conduct automated monitoring and self-monitoring of the knowledge 
level $[3,4,21,22]$. Using information technologies in the educational process should help teachers create meaningful, interesting, modern courses, which is especially important for such disciplines as mathematics and physics, which are the fundamental basis of natural science knowledge and are not just "random" facts and formulas [11]. Creating an open information educational environment is important for higher education because most of the time is spent on self-active work in teaching students. Using information technologies makes it possible to increase the effectiveness of communication between teachers and students, colleagues and makes getting knowledge more accessible for all categories of students, including people with disabilities.

\section{Conclusion}

The advantages of the "Open BMSTU" educational platform should include the ability to solve additional tasks that are not included in the curriculum for the seminar class because of the limited classroom time, but allow you to work out and merge the theoretical material in practice. Educational material availability and visibility are undoubtedly considered being the main factors of the modern educational process at the university.

Introducing remote access testing, which is carried out within the educational process through information technologies, allows for an active dialogue between the teacher and students. Using such technologies is necessary not only to simplify the learning process but also to form the educational and professional competencies of future graduates.

In general, the information technology capabilities use should not violate the integrity of the educational process, but should expand its capabilities by creating new educational resources. In other words, emerging new forms of the educational process should not distort the educational trajectory in any way, but should make it more convenient for mastering the growing resource base of knowledge. Information technologies should systematize the process of obtaining knowledge and contribute to the creation of accessible and rational forms of testing students' knowledge.

\section{References}

1. O.S. Erkovich, S.P. Erkovich, A.A. Esakov, I.S. Golyak, Formirovanie matricy kompetencij kak sredstvo proektirovaniya programmy uchebnoj discipliny [Formation of the Competence Matrix as a Means of Designing the Curriculum of an Academic Discipline], Fizi-cheskoe obrazovanie v vuzah [Physical Education in Universities] 18(3), pp. 27-31 (2012)

2. O.S. Erkovich, N.A. Zadorozhnyj, A.N. Morozov, M.L. Pozdyshev, S.L. Timchenko, "Russkij metod obucheniya» na kafedre fiziki pri podgotovke inzhenerov ["Russian Training Method" at the Physics Department for Training Engineers], Fizicheskoe obrazovanie v VUZah [Physical Education in Universities] 22(4), pp.5-19 (2016)

3. T.Yu. Tsibizova, V.M. Postnikov, S.B. Spiridonov, Analiz vliyaniya tekhnologij lekcij-vizualizacij na rezul'taty kontrol'nyh meropriyatij po uchebnym disciplinam [Analysis of the Impact of Lecture-Visualization Technologies on the Results of Control Measures in Academic Disciplines], Perspektivy nauki i obrazovaniya [Prospects for Science and Education] 3(33), pp. 358-363 (2018)

4. T.N. Noskova, T.B. Pavlova, O.V. Yakovleva, Nekotorye effekty informatizacii obrazovatel'noj sredy sovremennogo vuza [Some Effects of Informatization of the Educational Environment of a Modern University], Otkrytoe obrazovanie [Open Education] 20(3), pp. 24-30 (2016). 
5. T.V. Nikulina, E.B. Starichenko, Informatizaciya $i$ cifrovizaciya obrazovaniya: ponyatiya, tekhnologii, upravlenie [Informatization and Digitalization of Education: Concepts, Technologies, Management], Pedagogicheskoe obrazovanie v Rossii [Pedagogical Education in Russia] 8, pp. 107-113 (2018)

6. V.Y. Shurygin, L.A. Krasnova, Electronic Learning Courses as a Means to Activate Students' Independent Work in Studying Physics, International Journal of Environmental and Science Education 11(8), pp. 1743-1751 (2016)

7. A. Eitel, How repeated studying and testing affects multimedia learning: Evidence for adaptation to task demands, Learning and Instruction 41, 70-84 (2016)

8. N.A. Crowder, Automatic training by intrinsic programming, Teaching Machines and Programmed Learning, ed. A.A. Lumsdaine, R. Glaser Teaching Machines, Washington (1961)

9. B.F. Skinner, The technology of teaching, BF Skinner Foundation (2016)

10. A. Delbanco, College: What It Was, Is, and Should Be-Updated Edition, Vol. 82, Princeton University Press (2014)

11. A. Elby, Helping physics students learn how to learn, American Journal of Physics 69(S1), pp. 54-64 (2001)

12. M.G. Sergeeva, I.S. Samokhin, M.S. Mohammad Anwar, N.N. Bedenko, N.Z. Karavanova, T.Yu. Tsibizova, "Educational company» (Technology): Peculiarities of its implementation in the system of professional education, Espacios, 39(2), p. 24 (2018)

13. T.Yu. Tsibizova, N.G. Poyarkov, S.V. Mamaeva, A.V. Rubtsov, E.M. Plekhanova, V. V. Kolchina, I. N. Tonkavich, Forming a pedagogue's research competences in innovative educational environment, International Journal of Engineering and Technology (UAE), 7(4.38), p. 1243-1246 (2018)

14. P.J. Feltovich, R.J. Spiro, R.L. Coulson, Learning Teaching, and Testing for Complex Conceptual Understanding, Test theory for a new generation of tests, pp. 193-230, Routledge (2012)

15. L. Ding, N. W. Reay, A. Lee, L. Bao, Effects of testing conditions on conceptual survey results, Physical Review Special Topics-Physics Education Research 4(1), $010112(2008)$

16. O.Yu. Dement'eva, S.L. Timchenko, N.A. Zadorozhnyj, Sposoby izmereniya shiriny linii rezonansnogo pogloshcheniya $v$ usloviyah EPR [Methods for Measuring the Width of the Resonant Absorption Line in EPR Conditions], Fizicheskoe obrazovanie v vuzah [Physical Education in Universities], 22(4), pp. 77-87 (2016).

17. S.L. Timchenko, N.A. Zadorozhnyj, O.Yu. Dement'eva, Izuchenie razdelov atomnoj fiziki v laboratornom praktikume tekhnicheskogo universiteta [Study of Sections of Atomic Physics in the Laboratory Workshop of the Technical University], Fizicheskoe obrazovanie v vuzah [Physical Education in Universities], 24(2), pp. 98111 (2018)

18. M. Kim, J. Choi, J. Song, Developing a web-based system for testing students' physics misconceptions (WEBSYSTEM) and its implementation, Journal of the Korean Association for Research in Science Education 27(2), pp. 105-119 (2007)

19. T.F. Muqarrobin, H. Kuswanto, Development of an android-based physics e-book to ease students' physics learning And its influence on their learning achievement, American Journal of Engineering Research (AJER), 5(10) (2016) 
20. M. Hill, M.D. Sharma, H. Johnston, How online learning modules can improve the representational fluency and conceptual understanding of university physics students, European Journal of Physics, 36(4), 045019 (2015)

21. D.S. Goodman, F.J. Rueckert, J. O'Brien, Initial steps toward a study on the effectiveness of multimedia learning modules in introductory physics courses for engineers, ASEE Annual Conference and Exposition (2017)

22. R.A. Serway, J.W. Jewett, Physics for scientists and engineers with modern physics, Cengage learning (2018) 